\title{
An Unstable Ring Chromosome in a Female Infant with Hypotonia, Seizures, and Retarded Development
}

\author{
LEONARD ATKINS, ROBERT T. SCEERY, and MAURICE E. KEENAN
}

From the Departments of Pathology and Pediatrics, Harvard Medical School; the Fames Homer Wright Pathology Laboratories, the foseph P. Kennedy, Fr. Laboratories of the Department of Neurology, and the Children's Servicesw Massachusetts General Hospital, Boston, Massachusetts, U.S.A.

The occurrence of a ring autosome in human cells has been described in association with congenital abnormalities and mental retardation (Turner, Jennings, Den Dulk, and Stapleton, 1962; Wang, Melnyk, McDonald, Uchida, Carr, and Goldberg, I962; Genest, Leclerc, and Auger, 1963; Lucas, Kemp, Ellis, and Marshall, 1963; Bain and Gauld, 1963; de Grouchy, Lévêque, Debauchez, Salmon, Lamy, and Marie, I964; Gropp, Jussen, and Ofteringer, 1964; Gordon and Cooke, 1964). $\mathrm{A}$ ring $\mathrm{X}$ chromosome has been reported in a few cases of ovarian agenesis (Lindsten, 1963; Lüers, Nevinny-Stickel, and Struck, 1964), and ring chromosomes have been noted in neoplasms (Levan, 1956) and in irradiated cells (Bender and Gooch, 1962).

The present report describes an infant who was found to have mosaicism in cultured blood and skin cells. One cell line was normal and another line contained a ring chromosome in addition to the normal complement.

\section{Case Report}

This female infant was admitted to the hospital 7 days after birth because of apnoeic spells associated with cyanosis starting at ro hours of age. The pregnancy was uneventful with a normal delivery, birth weight $6 \mathrm{lb} .9 \mathrm{oz}$. $(2976 \mathrm{~g}$.) The parents were unrelated and normal, the father being 28 and the mother 27 years old. There were two normal brothers of the proposita, aged 5 and 3. There was no history of irradiation exposure.

Physical examination showed a hypotonic infant with an occasional high-pitched cry. The ears were large with tufts of hair protruding from the midportion of each helix. The finger- and toe-nails were poorly developed. Otherwise, the examination was negative.

The white cell and differential counts were normal, as

Received October 29, 1965.

* Supported by U.S. Public Health Service Research Grant No. NB-04662 from the National Institute of Neurological Diseases and Blindness. was a routine urinalysis. The serum calcium was $10 \cdot 20$ mg., phosphorus $5.7 \mathrm{mg}$., and blood sugar $63 \mathrm{mg}$./ $100 \mathrm{mli}$ A lumbar puncture yielded normal cerebrospinal fluid $\vec{\omega}$

The first four days in the hospital were uneventful On the fifth day there was another apnoeic spelg associated with cyanosis and lasting about 2 minutes. There were no unusual movements. An electroene cephalogram, an electrocardiogram, and X-rays films of the skull were normal. Subsequently, there were no further apnoeic spells, and the patient was discharged oreo the IIth hospital day.

Although phenytoinum sodium and phenobarbitonum were administered, apnoeic spells continued with tonio seizures during several febrile illnesses associated witls coryza. During the seizures the eyes rolled back, sh became rigid, and, after I-2 minutes, cried out, becam limp, and then went to sleep.

Motor development during the first year of life was slow. She smiled at 3 to 4 months and could raise hep head at 4 months. At the age of ro months she could roll over, sit up with support, crawl, and say 'da, da'? She was very hypotonic but jabbered and appeared aler? but 'lazy'. The first tooth erupted when she was 8 months old. From the IIth to I4th month there werf no further seizures, despite stopping phenytoinuna sodium and phenobarbitonum therapy and the occur rence of two febrile illnesses during this time.

Examination at the age of I4 months showed a well nourished, alert baby with marked hypotonia. The weight was $2 \mathrm{I} \mathrm{lb}$. $(9.5 \mathrm{~kg}$.), the height 35 in. $(89 \mathrm{~cm}$.) and the head circumference $48 \mathrm{~cm}$. No tonic necls reflexes or Moro reflex were demonstrable. The planta․ responses were extensor. There was no ankle clonuf bilaterally. The leg muscles were weak, and the patien was unable to sit without support, though she could crawl over obstacles. Speech consisted of jabbering There was no mongoloid slant to the eyes. The eyelashes were straight and elongated, measuring $I \cdot I \mathrm{~cm}$. in length. The irides were blue with Brushfield spots오 There was an alternating esophoria. Seven teeth had erupted. The ears were enlarged and low-set; the previously noted tufts of hair were no longer present.o The finger- and toe-nails were normal. Cutaneous dimples were present over the lateral condyles of th elbows and over both patellae. Examination of the ches 
TABLE I

CHROMOSOME COUNTS OBTAINED FROM CELLS OF PROPOSITA

\begin{tabular}{|c|c|c|c|c|c|c|c|c|c|}
\hline & 44 & 45 & 46 & 47 & 48 & $92(4 n)$ & $94(4 n)$ & Total & $\begin{array}{l}\% \text { Cells with } \\
\text { Ring Chromosome }\end{array}$ \\
\hline $\begin{array}{l}\text { Blood I, age I I dy. } \\
\text { Blood II, age I } 8 \mathrm{dy} \text {. } \\
\text { Skin, age I } 8 \text { dy. } \\
\text { Blood III, age } 7 \mathrm{mth} \text {. } \\
\text { Blood IV, age I } 3 \mathrm{mtn} \text {. }\end{array}$ & $\frac{\overline{1}}{\frac{1}{3}}$ & $\begin{array}{l}2 \\
2 \\
3 \\
4 \\
3\end{array}$ & $\begin{array}{r}102 \\
112 \\
136 \\
88 \\
252\end{array}$ & $\begin{array}{l}29 \\
41 \\
14 \\
20 \\
26\end{array}$ & $\begin{array}{l}\text { I } \\
\mathbf{I} \\
\end{array}$ & $\begin{array}{l}-2 \\
4 \\
2 \\
-\end{array}$ & $\begin{array}{r}\mathbf{I} \\
3 \\
\mathbf{I} \\
-\end{array}$ & $\begin{array}{l}134 \\
161 \\
160 \\
114 \\
284\end{array}$ & $\begin{array}{l}22.4 \\
26.7 \\
10 \\
17.5 \\
8.4\end{array}$ \\
\hline
\end{tabular}

and abdomen was negative, and the external genitalia were normal. An electroencephalogram at this time was normal.

Cytological Data. One normal-sized sex chromatin body was present in $36 \%$ of buccal mucosa cells and in $23 \%$ of cultured skin cells.

Four leucocyte cultures for chromosome studies were done by the method of Moorhead, Nowell, Mellman, Battips, and Hungerford (1960) at the ages of II days, I 8 days, 7 months, and 13 months. A skin biopsy specimen obtained from the patient when she was 18 days old was cultured by the method of Harnden (I960). Both blood and skin showed mosaicism with one normal cell line having 46 chromosomes and another line with 47 chromosomes, including a ring chromosome in addition to a normal complement (Fig. I). The chromosome counts and the percentage of cells with a ring chromosome are shown in Table I. A progressive loss of the ring chromosome in the four leucocyte cultures occurred so that from about $25 \%$ shortly after birth there was a fall to $8.4 \%$ in the latest culture done when the proposita was 13 months old. Although the total data obtained from cultured skin showed a much lower percentage of cells with a ring chromosome than a leucocyte culture done at the same time, earlier harvestings showed a percentage similar to the first two shortterm leucocyte cultures with a subsequent gradual elimination of the ring, so that after two months it was no longer present in the culture. The ring chromosome showed some variation in size, though in most cells its diameter was about equal to the length of a chromosome in Group 19-20 (Fig. 2). No cells were found to have 2 ring chromosomes.

Chromosome studies on cultured leucocytes of both parents and the two sibs were normal (Table I).

Autoradiographic studies with $\mathrm{H}_{3}$-thymidine were carried out to determine whether the ring chromosome replicated late as an $\mathrm{X}$ chromosome. No late-labelling pattern was found. Although certain regions of the late-replacing $\mathrm{X}$ tend to complete $\mathrm{DNA}$ synthesis before others (Atkins, Santesson, and Voss, 1965), and hence might cause some difficulty in identification in the case of a ring $X$, one would expect to find at least some of the late-replicating $\mathrm{Xs}$ to show diffuse heavy labelling. The latter was not found in this case.

Dermatoglyphic Patterns. A simian line was present in both palms. The atd angle was proximal, bilaterally. The fingerprints showed the following patterns bilaterally: I arch, II radial loop, III ulnar loop, IV ulnar loop, and V ulnar loop.

Erythrocyte Antigens. The family data are summarized in Table II. No unexpected combinations were found.

\section{Discussion}

The identity of the ring chromosome in this case cannot be established from the available evidence. Since the sex chromatin pattern was normal and the autoradiographic studies were negative, the ring was probably not derived from an X chromosome. Because ring chromosomes are known to be unstable, they can be of different size and contain different amounts of chromosome material in different cells. Therefore, size itself cannot be used as a criterion for identification. In some cases, the phenotype of the patient may give the clue to the identity of the ring chromosome that is present. In

TABLE II

\begin{tabular}{|c|c|c|c|c|c|c|c|c|c|c|c|c|c|c|c|}
\hline & ABO & $\mathbf{R h}$ & $F y(a)$ & $\mathbf{K}$ & $\mathbf{M}$ & $\mathbf{N}$ & $\mathbf{P}$ & Le $^{\mathbf{a}}$ & Le $^{b}$ & $S$ & $\mathbf{s}$ & $W r^{\mathbf{a}}$ & $\mathrm{Jk}^{\mathrm{a}}$ & $\mathrm{Jk}^{\mathbf{b}}$ & V \\
\hline \multirow{4}{*}{$\begin{array}{l}\text { Proposita } \\
\text { Mother } \\
\text { Father } \\
\text { Brother (aged 3) } \\
\text { Brother (aged 5) }\end{array}$} & \multirow{4}{*}{$\begin{array}{l}\circ \\
\circ \\
A_{1} \\
0 \\
0\end{array}$} & \multirow{4}{*}{$\begin{array}{l}\text { CDe/cde } \\
\text { CDe/cde } \\
\text { CDe/cde } \\
\text { CDe/cde }\end{array}$} & + & - & - & + & + & + & - & - & + & - & + & - & - \\
\hline & & & - & - & - & + & \multirow{2}{*}{\multicolumn{3}{|c|}{ 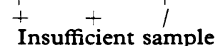 }} & - & + & - & + & - & - \\
\hline & & & + & - & - & + & & & & - & + & - & 1 & 1 & - \\
\hline & & & + & - & - & + & - & - & + & - & + & - & + & - & - \\
\hline
\end{tabular}


FIG. I. Metaphase plate and karyotype prepared from a cultured leucocyte. The ring chromosome $(R)$ is placed to the right of the 1 3-I 5 group.
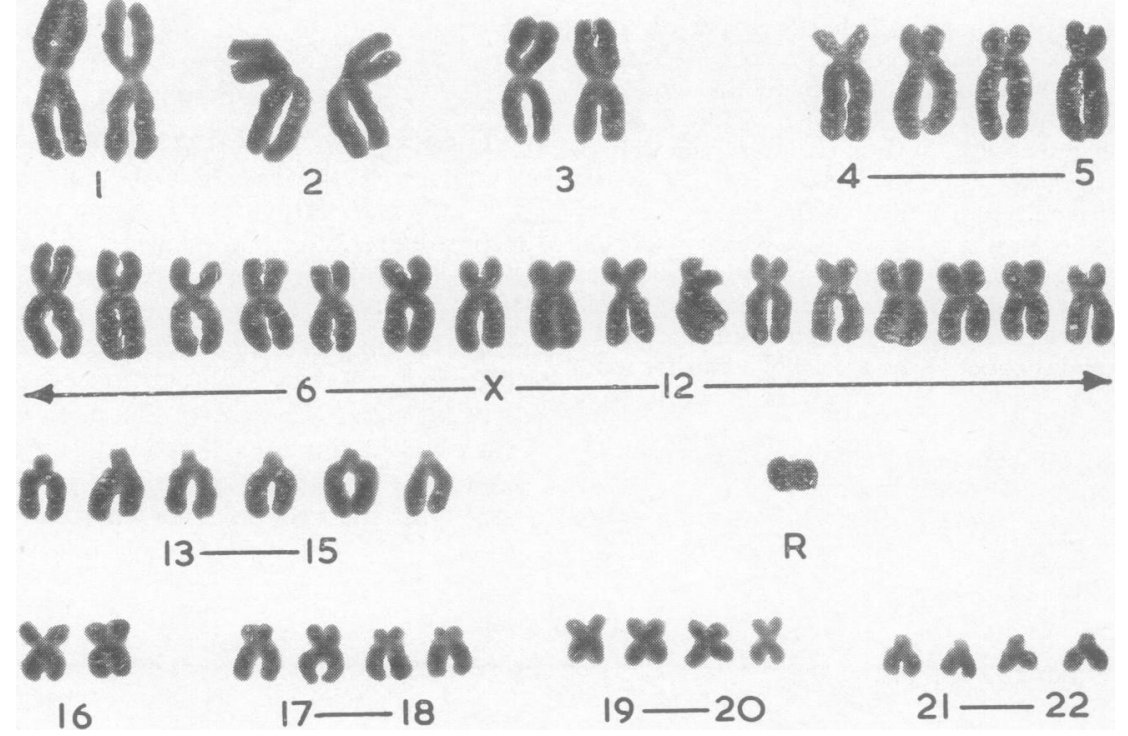

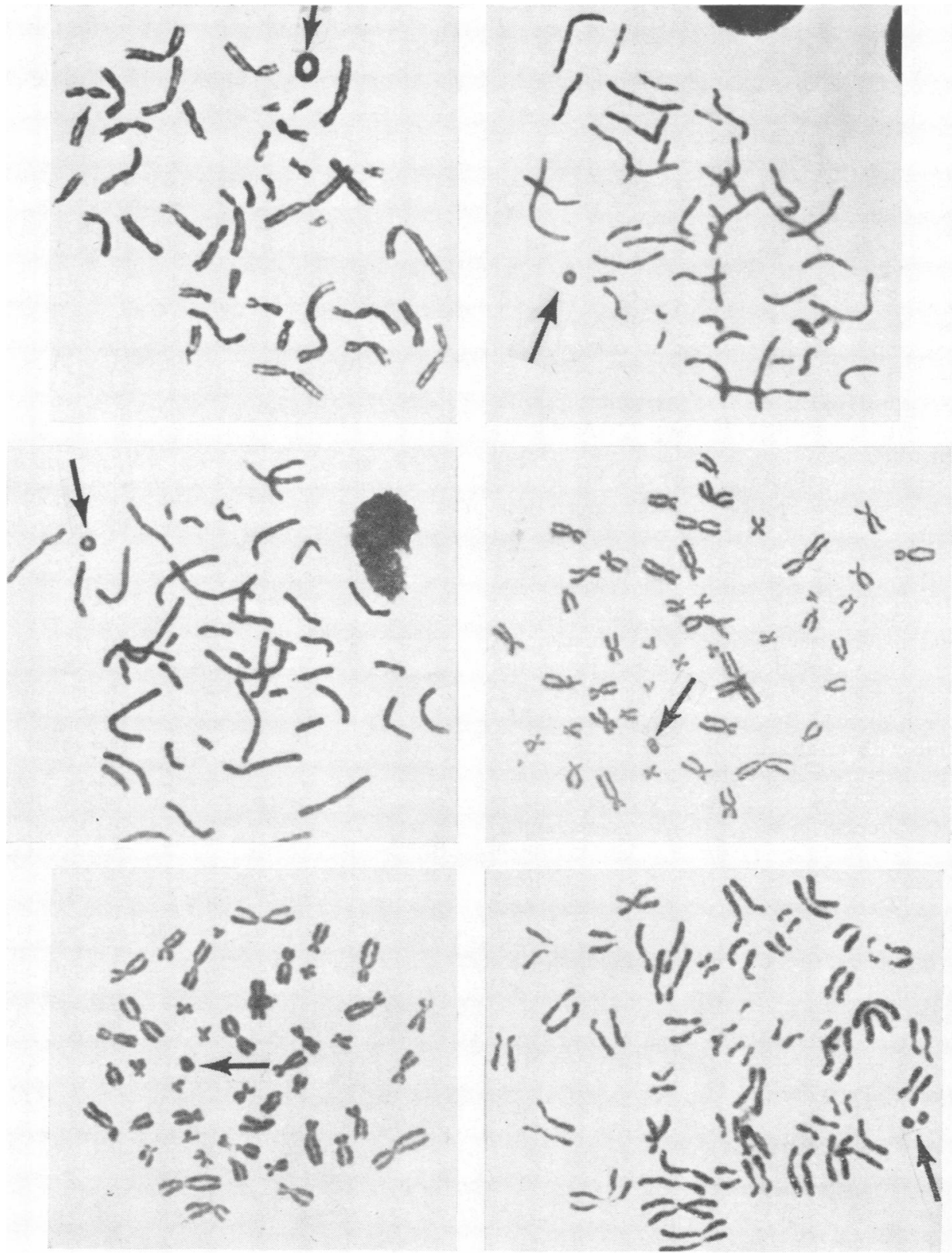

FIG. 2. Metaphase plates of cultured leucocytes showing some variation in the size and configuration of the ring chromosome (indicated by arrows). Two rings can be seen in the figure at lower right, in which most isochromatids are separated at the centromere. 
the present case, though phenotypically few stigmata associated with the known trisomy syndromes were present, the possibility of the ring being derived from a No. 18,21 , or the large acrocentric chromosome associated with the $\mathrm{D}^{1}$ trisomy syndrome cannot be excluded. Naturally, the ring may have arisen from any other autosome. Mosaicism with the presence of a normal cell line probably accounts for the comparatively few clinical abnormalities observed.

The cytological findings can be explained by a number of possibilities. Formation of the ring through loss of the distal ends of the arms of a chromosome with union of the broken ends of the centric fragment could have occurred in a parental gonad or during an early stage of the embryo. Subsequently, non-disjunction in meiosis or mitosis would give rise to a cell line with 47 chromosomes. Non-disjunction could have preceded the formation of a ring either in a parental germ cell or in the embryo. A formally possible, though much less likely, situation would involve ring formation in one parental gonad, and non-disjunction of the homologous chromosome leading to a gamete with 24 chromosomes in a gonad of the other parent before zygote formation. Gradual elimination of the unstable ring chromosome resulted in a predominant normal cell line and a diminishing line with 47 chromosomes. In maize, ring chromosomes are unstable with a tendency for small rings to be lost in mitosis and for large rings to show frequent changes in size as a result of breakage-fusion-bridge cycles (McClintock, 1938). In the case under discussion the instability of the ring chromosome was apparent over the course of 13 months. Eventual complete loss of the ring seems likely, and further follow-up studies are planned to confirm this. It is of interest that the ring was also gradually eliminated from skin cells in vitro. Lucas et al. (I963) noted a tendency for the ring in their case to be lost in vitro as the cultures aged. In the latter case the ring was relatively small, being derived from a No. I8 chromosome.

\section{Summary}

A 14-month-old female infant with muscular hypotonia, motor retardation, and seizures, is reported. Cytogenetic studies showed $46 / 47$ mosaice ism with an extra chromosome in the form of a ring The percentage of cells with a ring chromosome. decreased from about $25 \%$ shortly after birth $8.4 \%$ at age of 13 months, and prolonged culture of skin fibroblasts was associated with a gradual disappearance of the ring.

We wish to thank Misses Ida Leone, Mary Haucfo and Susan Fletcher for technical assistance. The erythrocyte antigen studies were done by Miss Susat Jago of the Blood Bank of the Massachusetts General Hospital.

\section{REFERENCES}

Atkins, L., Santesson, B., and Voss, H. (1965). Partial deletion an X chromosome. Ann. hum. Genet., 29, 89.

Bain, A. D., and Gauld, I. K. (1963). Multiple congenital abnofmalities associated with ring chromosome. Lancet, 2, 304.

Bender, M. A., and Gooch, P. C. (1962). Persistent chromosom aberrations in irradiated human subjects. Radiat. Res., 16, 44.

Genest, P., Leclerc, R., and Auger, C. (1963). Ring chromosomes and partial translocation in the same cell. Lancet, $I, 1426$.

Gordon, R. R., and Cooke, P. (1964). Ring-I chromosome and microcephalic dwarfism. ibid., 2, 1212.

Gropp, A., Jussen, A., and Ofteringer, K. (I964). Multiple congenit anomalies associated with a partially ring-shaped chromosonis probably derived from chromosome No. 18 in man. Nature (Lond. 202, 829 .

de Grouchy, J., Lévêque, B., Debauchez, C., Salmon, C., Lamy, Mด and Marie, J. (1964). Chromosome I 7-18 en anneau et malform\& tions congenitales chez une fille. Ann. Génét., 7, 17.

Harnden, D. G. (1960). A human skin culture technique used fo্] cytological examinations. Brit. F. exp. Path., 4I, 31 .

Levan, A. (1956). Self-perpetuating ring chromosomes in twe human tumours. Hereditus (Lund), 42, 366.

Lindsten, J. (1963). The Nature and Origin of $X$ Chromosom Aberrations in Turner's Syndrome. Almqvist \& Wiksell, Stockholm.

Lucas, M., Kemp, N. H., Ellis, J. R., and Marshall, R. (1963 A small autosomal ring chromosome in a female infant with congenital malformations. Ann. hum. Genet., 27, 189.

Lüers, T., Nevinny-Stickel, J., and Struck, E. (1964). Ring chromosomen bei Gonadendysgenesie. Geburtsh. u. Frauenheilk $24,173$.

McClintock, B. (1938). The production of homozygous deficien tissues with mutant characteristics by means of aberrant mitotic behaviour of ring-shaped chromosomes. Genetics, 23, 315.

Moorhead, P. S., Nowell, P. C., Mellman, W. J., Battips, D. M. and Hungerford, D. A. (1960). Chromosome preparations leukocyte cultures from human peripheral blood. Exp. Cell Res 20, 613.

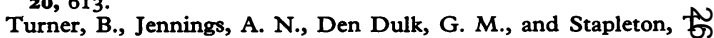
(1962). A self-perpetuating ring chromosome. Med.f. Aust., 2, 56. Wang, H. C., Melnyk, J., McDonald, L. T., Uchida, I. A., Cars, D. H., and Goldberg, B. (1962). Ring chromosomes in humao beings. Nature (Lond.), 195, 733. 